\title{
The Campaign: a case study in identity construction through performance
}

\author{
Matthew D. Riddle* \\ Faculty of Law and Management, La Trobe University, Bundoora, Australia
}

(Received 29 April 2008; final version received 16 July 2008)

\begin{abstract}
This article undertakes a detailed case study of The Campaign, a teaching and learning innovation in media and communications that uses an online educational role-play. The case study draws on the qualitative analysis of classroom observations, online communications and semi-structured interviews, employing an interpretive approach informed by models drawn from social theory and sociotechnical theory. Educational authors argue that online educational role-plays engage students in authentic learning, and represent an improvement over didactic teaching strategies. According to this literature, online role-play systems afford students the opportunity of acting and doing instead of only reading and listening. Literature in social theory and social studies of technology takes a different view of certain concepts such as performance, identity and reality. Models such as performative self constitution and actor network theory ask us to consider the constructed nature of identity and the roles of all of the actors, including the system itself. This article examines these concepts by addressing a series of research questions relating to identity formation and mediation, and suggests certain limitations of the situationist perspective in explaining the educational value of role-play systems.
\end{abstract}

Keywords: role-play; performance; identity; education; authentic learning

\section{Introduction}

Role-play has long been used as an educational tool to provide learners with a way to understand the real world. Since the advent of the World-Wide Web, online role-plays have become widely used in Australian tertiary institutions endeavouring to provide students with authentic learning opportunities (Brown, Collins, and Duguid 1989). It is argued in the education literature that through the performance of roles, students are able to appreciate a multitude of perspectives on real-world scenarios (Herrington and Oliver 1995). However, work in the area of social studies of technology and sociology asks us to look at the experience of reality and role-play through a different prism. The research reported in this article uses models drawn from social theory and sociotechnical theory to examine a series of related research questions, including how students become engaged with identities, how identities are mediated, and the extent to which roles in these role-plays are shaped by the system, the scenario, and the agency of the actors themselves. It does this through an in-depth analysis of an online role-play known as The Campaign, developed at The University of Melbourne. This analysis

*Email: m.riddle@latrobe.edu.au 
suggests the usual argument for the use of online role-plays on the basis that they are authentic learning environments, should be carefully reconsidered. It discusses the effects of surveillance in an online system on the performance of roles and suggests limitations in the situationist perspective in accounting for the self-constitution of identity through role-play.

\section{Authentic learning}

A central argument used to support the use of role-play environments in tertiary education is that they provide access for students to the world of doing and acting instead of simply receiving instruction through reading and listening. The idea that students should participate in their own learning through a form of practice has been mainstream in educational theory for a long time, yet it is still commonplace for tertiary courses to be taught through the heritage method of lectures and seminars. Where methods such as role-play are used, therefore, the argument is that students will be more fully engaged through practice in an authentic learning environment.

Brown, Collins, and Duguid (1989) suggest that the activity and context in which learning takes place are generally regarded as ancillary, distinct, and neutral with respect to what is learned. They argue that this common assumption is clearly incorrect, drawing on Vygotsky's (1978) theory that knowledge is fundamentally social in nature. Cognitive skills are, they contend, the products of social interactions within an individual's environment rather than being innate. Learning and acting are therefore not to be thought of as somehow distinct functions. There is a life-long process of learning how to act.

This situationist approach to learning contends that individuals learn from the environment within which they find themselves. Learning is situated and therefore we should focus on providing rich, active learning environments rather than dull and inert classrooms. Furthermore, learners tend to pick up cultural behaviours and gradually start to act within the norms of that culture through observing and practicing in situ. The problem, according to these authors, is that schools use classroom tools such as dictionaries and formulae in a different way from practitioners, so students can do well when assessed but may not be able to use a chosen domain's conceptual tools in practice. They therefore define authentic learning activities as 'ordinary practices of the culture' (Brown, Collins, and Duguid 1989, 36).

\section{Online educational role-plays}

Role-play is a relatively common teaching practice, particularly in primary and secondary school settings. Traditional role-play activities involve students enacting some kind of story for the purposes of gaining a more complete understanding of a concept or issue. Milroy $(1982,41)$ argues for the validity of role-play as a learning technique because it is an 'opportunity for discovering more about human behaviour and for acquiring the kind of information that will help people cope more effectively with their own relationships'. Freiberg (1996) advocates the use of improvisation strategies such as role-play for the purpose of involving students more actively in their learning, encouraging collaboration among students, improving the development of shared meanings, and linking varied curriculum areas together. Role-plays are, Freiberg says, a safe way of 'making learning real' (Freiberg 1996, 337). 
Despite not being widespread prior to the existence of the World-Wide Web, online role-plays were being used in higher education in Australia as early as 1992. Vincent describes an email role-play used for teaching political science students about the Middle East peace process during this time (Swart 1992). Students took on the roles of important public figures involved in a fictional scenario based on events in the Middle East. Students from the University of Melbourne were linked up with students in Texas studying the same issues. The exercise culminated in a telephone conference between the two student cohorts in which the students dressed as their characters.

The development of the Middle East role-play simulation (Vincent and Shepherd 1998) led to a series of others at the University of Melbourne, including DRALE Online (Riddle and Davies 1998) and The Campaign (Hirst, Riddle, and Young 2005), and influenced other online role-play developers in Australia (Kinder, Fardon, and Yasmeen 1999). Describing a learning design architecture that follows on from Vincent and Shepherd's (1998) work, Ip, Linser and Naidu (2001) emphasise the facility of role-play simulations in the acquisition of practical skills, as well as their ability to provide a context for those skills through the use of goal-based scenarios (see also Ip and Morrison 2001).

\section{Performance, identity and actor networks}

An investigation of online role-plays that attempt to allow students to see themselves as professionals calls into view a number of important theoretical considerations. The concepts of performance and identity and how they relate to one another are of particular interest to the discussion. It is useful in this context to recall the work of Althusser (1977), who posits a theory about how individuals (actors and their roles) are defined and reflected by ideological structures in the world around them. Althusser (1977, 160) coins the term interpellation to mean the process by which individuals are recruited and transformed into subjects. He gives the example of a police officer who hails a pedestrian by calling 'Hey, you there!'. The individual instantly recognises that they are the subject who is being hailed, and in that moment recognises and declares him or herself as a subject. Indeed, Althusser says, we are 'always and already' interpellated (or hailed) as subjects by ideology.

Goffman's (1959) performative self-constitution thesis contends that we develop our sense of self by performing roles in life. In order to perform a role successfully, we must make our audience believe our performance. The performer may or may not believe their own performance. Sometimes the act begins as a cynical exercise and ends with self-belief, according to this theory, and sometimes this sequence is in reverse. Goffman $(1959,32)$ uses the term front for the 'expressive equipment of a standard kind intentionally or unwittingly employed by the individual during his performance.' The front is not limited to linguistic practices, and includes a setting (an office, for example) and a personal front comprising the appearance and manner of the performer. Clothing, physical characteristics, speech patterns, and gestures are all important parts of the performance.

When considering the way that individuals and technology interact in relation to concepts of identity, the topic of power must also be examined. Actor network theory (ANT) argues that social theories must take into account the special nature of humans and their relationship with technology. Thus 'every human interaction is sociotechnical' (Latour 1994, 806). ANT does away with the distinction between human subjects and non-human objects in order to investigate the way that humans and non-humans 
are actors linked through numerous sociotechnical associations (Latour 1994, 804). It should be noted that this notion of agency is contested by the work of authors such as Pickering (1995, 9-20) and Ihde (1990, 26).

Online networks arguably provide a new mechanism for surveillance over students. Foucault (1984) provides a useful and provocative model for thinking about the effect of surveillance on individuals. He argues that it is through the construction of a hierarchical apparatus for observation that individuals are subjugated and redefined, citing examples such as the design and layout of military camps that allow every action of the soldiers to be seen (Foucault 1984, 189). This slightly darker view and its effect on the way that individuals interact within online education systems must be taken into account. For example, Foucault argues that educational examinations use techniques of observation together with techniques to normalise judgement in order to qualify, classify, and punish (Foucault 1984, 197). Online systems provide new opportunities to capture and observe interactions in a more comprehensive way.

\section{The Campaign}

The Campaign was conceived as a role-play scenario by Dr Sally Young at The University of Melbourne in the winter of 2003. It is designed to enable an online roleplay between political advisers and journalists covering an election campaign, and culminating in a 'live' press conference. Students would be divided into teams of Advisors and Journalists and paired up with a member of the opposite team. The system simulates the final four weeks of an election campaign over eight weeks' time, with content specific to each week of the campaign being time-released at two-week intervals. Students log on as either a Journalist or an Adviser, with Tutors logging in from a Tutor's page. The student role-play participants see documents that pertain only to their role, and can create new documents such as articles and press releases to be saved in a Work Folio or sent to another role-play participant. A To Do list shows a series of tasks to be completed during one week of the campaign, and a 'placemarker' function displays the current week's To Do list. At various stages throughout the role-play, the To Do list links to media clips, including audio and video material created specifically for the simulation. The scenario was designed to include some surprise events that would be introduced primarily through the use of these media clips and leading to ethical dilemmas.

The Campaign was first used in Semester 2, 2004 and again in Semester 2, 2005. The system was designed for the most part to simulate a political campaign as experienced by a Journalist or Adviser as closely as possible. However, it included certain features that replicate university educational processes, such as instructions to the students, a discussion area, and a process for submitting documents for assessment. The online system described above thus represents a hybridised partial replication of two existing social systems: a political campaign and the traditional university education system.

There are many ways in which the behaviour of participants in The Campaign can be interpreted as they established their roles. The purpose of this study is to examine the ways in which students become engaged with one or more identities, and in particular with their vocational identity. The paper focuses on how the online nature of the role-play affects this engagement including how students get into role and the influence of surveillance. Poster (2001) applies Althusser's (1977) concept of 
interpellation to online communications, and the interpretation of the communications within The Campaign will follow and extend this path.

\section{Methodology}

The Campaign was used in a postgraduate Media and Communications program at the University of Melbourne. Students enrolled in Strategic Political Communication in the second semester of 2005 were approached to be involved in the study. All participants were briefed and signed a consent form. The project received approval from the university's Human Ethics Committee.

Primary data included classroom observations, online communications using The Campaign Mail Tray and email, semi-structured interviews with five self-nominated students and technical and educational design documents from The Campaign and other similar online role-plays. Student pairs as Journalist/Advisor were: James/Thea, Kirsten/Noni*, Frida/John, Yvette/Heather*, Brian/Xuan*, Guido/Stacey*, Graham*/ Josie (pseudonyms are used, and asterisks indicate those who were interviewed). Interviews were transcribed in full and the resulting transcripts, along with selected extracts from the students' communications and extracts from the design documents for the system were then analysed. This methodology drew upon grounded theory coding techniques in social science described by Strauss (1990), Neuman (2003) and Seale and Kelly (1998). These data were then interpreted using theoretical constructions of actors, subjects, identities, roles and performances, drawn from social theory and sociotechnical studies.

\section{Results and discussion}

\section{Getting into the role}

Participants were asked how they went about getting into their role, including what they had been told in class, what they learnt by consulting the system, and what they drew from their own experience. Three of the students interviewed felt they lacked a good understanding about the role they were going to play, and indicated some uncertainty about their approach. Noni chose her role as an Adviser because she felt she already knew what would be expected of a Journalist and preferred to explore a more unfamiliar role. Xuan said he had a feeling of 'panic' when confronted by the challenges of his role, and Heather felt the expectations of acting in the role of Adviser were 'huge'. All of these students referred to relying on their own research (guided by a reading list in the system) and what they could learn from reading documents that were provided to them during the exercise.

Advisers were given access to a set of electronic documents specific to their role including a Letter of Offer of Employment, a Staff Card, and various messages from their Candidate intended to direct their attention to the tasks expected of them in their role. Journalists received equivalent documents and directions from their Editor. These documents provide a kind of character profile for the role and an outline of the role-play scenario. Students who identified themselves as less confident tended to use a pattern of studying documents, engaging in set tasks, and then contacting their partnered student by email or at face-to-face meetings. While they sometimes met face-to-face with other students to negotiate the nature of their roles in the role-play, they also used the online communication as a way to take their time and test out the 
way they should interact in role. Students who were more confident had an understanding of some of this detail, so sometimes reported spending less time reading background material. Yet they all still spent time and effort researching their roles, sometimes asking experts to whom they had privileged access.

Graham signed off his messages as 'Political Correspondent' above the title of the fictitious newspaper The New Times, which was typical of students engaging in online communications within the System. Almost all of the students tended to use a friendly and professional tone in their initial contact in The Campaign. As soon as this initial contact was made, Graham's messages began to assume a more informal tone, although he continued to use his title and employer at the end of his messages. There is no doubt that building a good working relationship was high on the agenda, because Graham referred to the dependence of Journalists on the Advisers to feed them content during the role-play. Graham perceived that the Advisers were really in control of the way that the role-play played out. Most of the students interviewed felt that Journalists were somewhat dependent on Advisers in this way. Thus, the role-play is establishing a sub-text of power distributions at the same time as asking students to go through the pragmatic or instrumental requirements of the role.

Graham interpellates Josie as an Adviser through the use of careful linguistic practices he associates with being a Journalist. He, in turn, is interpellated as a Journalist through his communications with her. Both are also interpellated by the system through the presentation of role-specific documents and cues. These features are to be expected of a role-playing system built around the concept of authentic learning. It is clear that these characteristics are successful in signifying something to the students, referring to a complicated set of social meanings, and that these meanings are then passed on. Althusser $(1977,170)$ argues that the mechanisms defining roles that individuals play in society are the means by which the social structure are reproduced, using vocational training as an example. The analysis of the design of, and communications within, these online role-plays reveals the particular linguistic techniques through which this mechanism is realised. At the same time these social meanings engage the students in their vocational identity, they reproduce themselves.

\section{Going off the radar}

Part of the role of the system was to monitor what students did. All discussions were recorded, and everything the students did in the system was logged. Foucault's (1984) ideas about observation and its effects on individuals come into play here. By analysing the effect of surveillance, we can get a clearer picture of the way the sociotechnical network mediates the identities of the role-play participants.

The relevance of this question to the particular roles students chose to perform and the way they went about performing them was made apparent somewhat by chance, due to a minor technical problem that emerged with the system. Student-to-student communications, handled by a function called the Mail Tray, sometimes failed. As this was crucial to the way that the role-play was conducted, students found other ways to contact each other, most of the time using private email. An analysis of some of the communications that students engaged in when they were outside of the system reveals that they almost always contacted each other as students, while inside The Campaign system they were almost always in character as Journalists and Advisers.

When asked about how and why they did this, students were quite forthcoming. Stacey commented that the layout of the pages and menus in the system made it clear 
that this was an 'Adviser space', saying, 'the very act of logging on emphasises that, as it demands a very clear and conscious act of entering a gate'. She added that she had the feeling that the lecturer could assess their communications in the system, and that it was a public, class space rather than one for private interaction between individuals. Thus the system interpellated students in a complex way. While on the radar, in order to play their role as Student in a conscientious way, they must play the role as Journalist or Adviser. Outside the system, the student may act as a student without the added layer involved when playing the assigned role. Despite this, the process of contacting each other in private outside the system involved some interesting negotiations in terms of how in-role the interactions would become. Figure 1 illustrates this using one of the first email messages Stacey sent to her Journalist partner Guido during the role-play.

Reflecting on this email, Stacey commented that it was particularly interesting because it was more in her role as an Adviser than later messages:

I was actually being Adviser me in that one. That message was sussing out how far 'in role' he was prepared to be, i.e. whether he was prepared to play the game outside the system. I quickly concluded he was not, though, so it just became chit chat between people in a class together, talking about our adviser and journo selves in third person (and with a certain amount of disapproval, I think you will find!). (Stacey, email, 26 February 2006)

Their comments reveal that the students were still driven by their tasks but either did not feel the need to keep up their assigned roles when communicating in a more private online setting, or alternatively, felt the need to reassert their roles as Friends and fellow Students when they could. While "off the radar", they would typically send a short informal note in the body of an email message while sending a more formal document in their Journalist or Adviser role as an attachment. Thus, while the system affords the movement in and out of roles by interpellating the actors involved, it also

\section{Hi, Guido, \\ It was a pleasure to meet you the other day. \\ You will recall that we were discussing whether or not Jenny Jones would stand for Warriwa.}

Well, you might be interested to know that she has now officially announced she will stand.

I've attached an advanced copy of the press release for your information.

Please do not hesitate to call if you have any questions, want to follow up on anything, or I can be of any other assistance.

\section{Regards}

\section{Stacey Carruthers}

\section{Senior Adviser to Jenny Jones}

Figure 1. Email extract from adviser student Stacey to journalist Guido. 
has an important role in constraining and normalising their behaviour through a process of surveillance (Foucault 1984).

Sociologist Erving Goffman $(1959,166)$ describes communications out of character as going backstage. According to his theory of the presentation of self, when two parties or teams interact, they tend to stay within character. That is, they maintain the line that is acceptable to all parties present. However, at moments of crisis, or when the audience is no longer present, they may engage in backstage familiarity. Performances backstage can include 'mock role-playing and uncomplimentary terms of reference', and are commonly characterised by derogation of the audience and what Goffman calls staging talk: discussion and analysis of aspects of the staging.

In the case of The Campaign, communications of a collusive nature between Journalists and Advisers that may be unacceptable inside the System are possible in email. The expressive equipment (or front) for Journalists and Advisers can be used inside the System and dropped outside of it. The purpose of their email communications is obviously to set up a commonality, not between Journalist and Adviser, but between student and student. In establishing this solidarity, Guido and Stacey can be seen to be setting up another front that is acceptable to them. It is not a matter of dropping an artificial front to reveal a reality - it is the change of audience that determines the need for a new front to be established. In other words, when they are off the radar, classmates interpellate each other as classmates. Goffman's thesis is that it is through presenting ourselves in different ways that we construct the self. It is my contention that online role-plays such as The Campaign provide the means for another front through which the self can be performed. The Campaign interpellates Guido and Stacey in the less familiar roles of Journalist or Adviser in order to make these roles more familiar, but it does not prevent them from interpellating each other in other ways as well. Cynical performance is at one end of a spectrum for Goffman, with being taking in by one's own act at the other (Goffman 1959, 30). If we accept that we perform ourselves in everyday life, it cannot be said that Guido and Stacey are really students who are performing as Journalist and Adviser when they also perform themselves as students.

\section{Conclusion}

This discussion has argued that theoretical models drawn from social theory and sociotechnical studies provide a new way to view online educational role-plays. Although online role-plays are clearly useful for learning, they are not as authentic as they are usually portrayed; particularly in so much as the nature of authenticity itself is problematic when considering identity. Too often the literature treats authenticity and identity as straightforward and unproblematic. Certain aspects of online role-plays that are unreal can be seen to enhance the ability of students to take on new roles and learn new professional skills. This suggests that future work may involve a reconsideration of the application of the theory of authentic learning to online role-plays with regard to epistemology, and further application of theories of performative self-constitution. Educational theories based on situated cognition (Brown, Collins, and Duguid 1989) suggest that role-plays work because they place learners within realistic situations in which they must act. However, following the theory of performative self-constitution, we might reinterpret the situation as the setting. We must include the personal front of the actor in any comprehensive description of the learning process through online role-plays. 
A limitation of authentic learning that emerges from this view is its lack of an account of the appearance and manner - in other words, the individual's expressive equipment, including those elements that are conscious and those that are not. The theory of authentic learning focuses on an account of how social interactions with the real world enhance learning, however by doing so the importance of these aspects of the individual are downplayed. In addition, by considering that situational learning may have more to do with providing learners with a setting that enables them to selfconstitute their roles and interpellate others, the importance of authenticity is thrown into question. One advantage of this is that we may be relieved of the burden of proving that a learning environment is actually authentic.

This analysis also suggests that current educational theory on online role-plays depends on a contested view of epistemology because it is often based on a conception of the learning process as being about acquiring knowledge through interacting with an objective reality.

\section{Acknowledgements}

The work in this article is an adaptation of a thesis submitted for my MA, entitled The roles actors perform: Role-play and reality in a higher education context, available online at: http://eprints.infodiv.unimelb.edu.au/archive/00002885/. Research for this thesis was supported by The Research Training Scheme from the Department of Education, Science and Training. The project grew out of discussions with Dr Michael Arnold and Dr Martin Gibbs.

\section{References}

Althusser, L. 1977. Ideology and ideological state apparatuses. In Lenin and philosophy and other essays, ed. B. Brewster, 127-87. London: Unwin. http://www.marx2mao.com/ Other/LPOE70NB.html

Brown, J.S., A. Collins and P. Duguid. 1989. Situated cognition and the culture of learning. Educational Researcher 18, no. 1: 32-42.

Foucault, M. 1984. The means of correct training (from Discipline and punish). In The Foucault reader, ed. P. Rabinov, 188-205. London: Penguin.

Freiberg, H.J. 1996. Universal teaching strategies. Boston, MA: Allyn and Bacon.

Goffman, E. 1959. The presentation of self in everyday life. Garden City, NY: Doubleday.

Herrington, J., and R. Oliver. 1995. Critical characteristics of situated learning: Implications for the instructional design of multimedia. Paper presented at Australian Society for Computers in Learning in Tertiary Education (ASCILITE) Conference, December 4-6, in Melbourne, Australia.

Hirst, D., M. Riddle, and S. Young. 2005. Maintaining the momentum throughout The Campaign: Role-play in political communication. Paper presented at Australian Society for Computers in Learning in Tertiary Education (ASCILITE) Conference, December 4-7, in Brisbane, Australia.

Ihde, D. 1990. Technology and the lifeworld: From garden to earth. Bloomington, IN: Indiana University Press.

Ip, A., and I. Morrison. 2001. Learning objects in different pedagogical paradigms. Paper presented at Australian Society for Computers in Learning in Tertiary Education (ASCILITE) Conference, December 9-12, in Melbourne, Australia.

Ip, A., R. Linser and S. Naidu. 2001. Simulated worlds: Rapid generation of web-based roleplay. Paper presented at AusWeb01: Seventh Australian World Wide Web Conference, April 21-25, in Coffs Harbour, Australia.

Kinder, J., M. Fardon and S. Yasmeen. 1999. Offline or online? A simulation exercise in a first year international politics unit. Paper presented at Australian Society for Computers in Learning in Tertiary Education (ASCILITE) Conference, December 5-8, in Brisbane, Australia. 
Latour, B. 1994. Pragmatogonies: A mythical account of how humans and nonhumans swap properties. The American 37, no. 6: 791-808.

Milroy, E. 1982. Role-play: A practical guide. Aberdeen, UK: Aberdeen University Press.

Neuman, W.L. 2003. Social research methods: Qualitative and quantitative approaches. London: Allyn and Bacon.

Pickering, A. 1995. The mangle of practice: Time, agency, and science. London: University of Chicago Press.

Poster, M. 2001. What's the matter with the Internet? Minneapolis, MN: University of Minnesota Press.

Riddle, M., and M. Davies. 1998. DRALE online: A computer mediated communication environment for teaching law, FlexibilITy: The next wave? Paper presented at Australian Society for Computers in Learning in Tertiary Education (ASCILITE) Conference, December 14-16, in Wollongong, Australia.

Seale, C., and M. Kelly. 1998. Coding and analysing data. In Researching society and culture, ed. C. Seale, 146-63. London: Sage.

Strauss, A.L. 1990. Basics of qualitative research: Grounded theory procedures and technique. Newbury Park, CA: Sage Publications.

Swart, R. 1992. Changing the way we teach and learn [videorecording]. Produced by the Television and Optical Disc Development Unit for Interactive Multimedia Learning Unit, Parkville: University of Melbourne.

Vincent, A., and J. Shepherd. 1998. Experiences in teaching Middle East politics via Internetbased role-play simulations. Journal of Interactive Media in Education 98, no. 11. http:// www-jime.open.ac.uk/98/11/vincent-98-11.pdf.

Vygotsky, L.S. 1978. Mind in society: The development of higher psychological processes. Cambridge, MA: Harvard University Press. 